University of Nebraska - Lincoln

DigitalCommons@University of Nebraska - Lincoln

Infochemical-tritrophic Interactions of Soybean Aphids-host Plants-natural Enemies and Their Practical Applications in Pest Management

Junwei J. Zhu

USDA-ARS, jerry.zhu@ars.usda.gov

Follow this and additional works at: https://digitalcommons.unl.edu/usdaarsfacpub

Zhu, Junwei J., "Infochemical-tritrophic Interactions of Soybean Aphids-host Plants-natural Enemies and Their Practical Applications in Pest Management" (2011). Publications from USDA-ARS / UNL Faculty. 1333.

https://digitalcommons.unl.edu/usdaarsfacpub/1333

This Article is brought to you for free and open access by the U.S. Department of Agriculture: Agricultural Research Service, Lincoln, Nebraska at DigitalCommons@University of Nebraska - Lincoln. It has been accepted for inclusion in Publications from USDA-ARS / UNL Faculty by an authorized administrator of DigitalCommons@University of Nebraska - Lincoln. 
CHAPTER 10

\title{
Infochemical-tritrophic Interactions of Soybean Aphids-host Plants-natural Enemies and Their Practical Applications in Pest Management
}

\author{
Junwei J. Zhu
}

\begin{abstract}
The soybean aphid, Aphis glycines Matsumura, is a newly invasive insect species that seriously threatens U.S. soybean production. This aphid pest has kept haunting many soybean growers by developing large colonies on soybeans in North America since 2000. Since its first appearance in Wisconsin, it has spread to over half of US states and southern provinces in Canada. The heavy infestation of this pest whittles soybean growers' profits and causes hundreds of million dollar losses. The present chapter will mainly describe efforts in studying aphid chemical ecology and sensory physiology for understanding how male aphids find their mates and host plants. It will also cover research efforts to understand host plant associated volatiles being used as cues for overwintering host plant location. In addition, findings on how soybean plant defensive system works against aphid infestation, as well as how those induced plant volatiles are used by aphid's natural enemies for prey location will be presented. Finally, the use the basic understandings for developing useful tools for soybean aphid practical control will be discussed.
\end{abstract}

Keywords infochemicals, tritrophic interactions, host plant, natural enemy, mating disruption, integrated pest management

\subsection{General introduction}

Soybean aphids, Aphis glycines Matsumura, are newly-invasive aphid pests that have caused significant economic losses to U.S. soybean production. This aphid pest tends to develop large colonies on soybeans, Glycine max, in North America (Ragsdale et al. 2004). Since their first being found in Wisconsin soybean fields,

Junwei J. Zhu

Agroecosystem Management Research Unit, USDA-ARS, Room 5, Entomology Hall, University of Nebraska, East Campus, Lincoln, NE 68583-0938, USA

E-mail: Jerry.Zhu@ars.usda.gov 
they have spread to over 20 US states and southern provinces in Canada (Soybean aphid watch 2003). The infestation of this pest whittles soybean growers' profits and causes hundreds of million dollar losses (CNN News, Nov. 25, 2003; Chicago Tribune Business News, Oct.11, 2003, and data from Midwest Soybean Aphid Workshop, Feb. 5, 2004).

The soybean aphid has a complex life cycle with more than 15 generations per season living on the secondary host, G. max. During the autumn, the soybean aphid producing winged females (gynoparae) that fly from soybean fields searching for their primary host plant, the common buckthorn, Rhamnus cathartica or R. alnifolia in the U.S. (Voegtlin et al. 2004). Once on buckthorns, gynoparae produce pheromone-emitting wingless female offspring (oviparae). Winged males are attracted to oviparae via a specific sex pheromone blend produced from glands on the hind legs of female aphids (Zhu et al. 2006). After mating, oviparae lay eggs that overwinter on the buckthorn.

\subsection{Sex pheromone of aphids}

Oviparae of soybean aphids produce both $(1 R, 4 \mathrm{a} S, 7 S, 7 \mathrm{a} R)$-nepetalactol and $(4 \mathrm{a} S, 7 S, 7 \mathrm{a} R)$-nepetalactone, which are the two most common aphid pheromone compounds identified from a number of other aphid species (Goldansaz et al. 2004, Boo et al. 2000; Pickett et al. 1992; Dawson et al. 1990). The pheromone blend identified at a specific ratio of 35:65 of the two compounds, $(1 R, 4 \mathrm{a} S, 7 S, 7 \mathrm{a} R)$-nepetalactol and $(4 \mathrm{a} S, 7 S, 7 \mathrm{a} R)$-nepetalactone, from $A$. glycines is highly attractive to conspecific males and gynoparae (Fig. 10.1, Zhu et al. 2006). This also indicates that gynoparae are capable of using pheromone compounds as cues for overwintering host plant location. Further evidence has shown that leaves of buckthorns release less volatiles after the appearance of gynoparae and pheromone-producing females ( $\mathrm{Zhu}$, unpublished).

\subsection{Pheromone applications in aphid control}

The use of synthetic sex pheromone to disrupt mating behavior has become a widely accepted and increasingly used integrated pest management (IPM) tool for suppressing populations of several key lepidopteran pests of agricultural crops and tree fruits around the world (Baker et al. 1997; Sanders 1997). Recent studies have shown that males of several aphid species can be selectively attracted to traps releasing synthetic aphid pheromones and gynoparous female aphids to host plant associated volatiles and sex pheromones at a relatively long distance (Campbell et al. 1990; Hardie et al. 1992, 1996; Boo et al. 2000; Lösel et al. 1996a, b). Some of the males have been further observed to orient towards pheromone traps against surprisingly strong winds. The sensory adaptation of soybean aphid antennal responses to the two pheromone compounds have been first demonstrated by Zhu et al. (2006) (Fig. 10.2). These recent findings are 


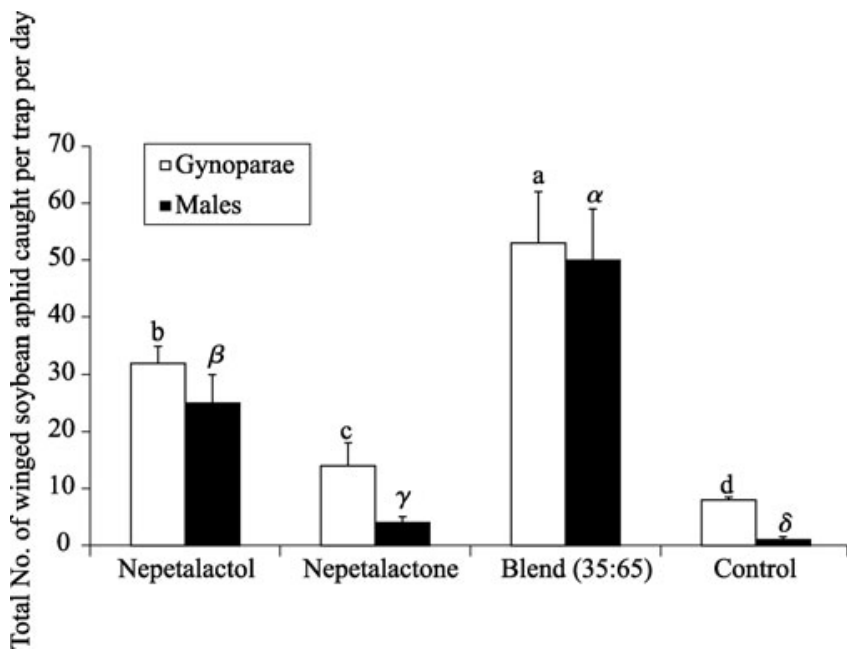

Fig. 10.1 Total number of male and gynoparous soybean aphids caught in traps with different combinations of identified sex pheromone compounds in 2001. Means with different letters on top of the bars indicate significant differences. $(N=10$, for gynoparae, $F=75.42 ; \mathrm{df}=3,20 ; P<0.001$, for males, $F=99.04 ; \mathrm{df}=3,36 ; P<0.001)$.

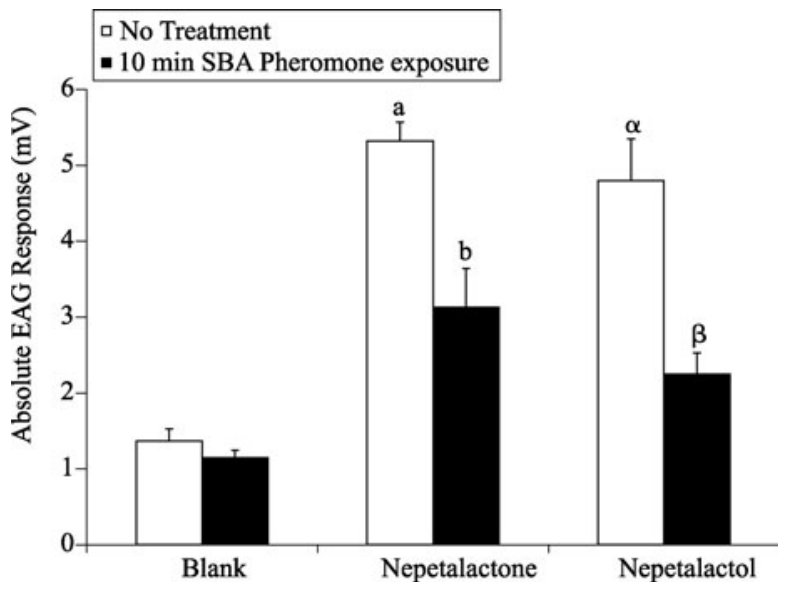

Fig. 10.2 Comparisons of absolute EAG responses of male soybean aphids preexposed with higher dosages of aphid pheromones to those without pre-exposure. Means with different letters on top of the bars indicate significant differences (Student $T$-test, $N$ $=12$, for nepetalactone, $t=5.08, P<0.001$; for nepetalactol, $t=3.54, \mathrm{P}<0.005$, for blank, $t=1.18, P>0.05)$.

encouraging for the potential deployment of mating disruption using sex pheromones in soybean aphid control. 
Another IPM component, mass trapping of insect pests using sex pheromones or host plant volatiles (as synergists), has also shown renewed promise as a population management tool (Kobayashi et al. 1981; Smit et al. 2001) for both moth and beetle pests. Mass trapping of male soybean aphids, as they leave soybean fields to locate females on the winter host, using inexpensive trap designs placed at the edges of soybean fields may be a feasible approach. Likewise, mass trapping of gynoparae leaving soybean fields may reduce population densities of overwintering aphids. The field trapping results shown in Fig. 10.1 indicate gynoparous soybean aphids respond to their female pheromones as well. Disruption of the ability of these gynoparae to fly to winter host plants by diverting them with the same sex pheromone dispensers that disrupt mate finding may further reduce the production of sexually reproductive female soybean aphids, thereby adding to the reduction in the overwintering population caused by mating disruption alone.

Sex pheromones have become very important tools for monitoring agricultural pest populations, and provide critical information for growers to take actions on pest outbreaks. Currently, soybean aphid population density monitoring in the field relies heavily on traditional field scouting, which is laborious and timeconsuming. Morphological studies indicate that antennae of spring and summer winged soybean aphids (alatae) soybean aphids contain placoid sensilla (secondary rhinaria) with olfactory receptor neurons that respond to the identified sex pheromone components (Du et al. 1995; Zhu and Park, 2005; Zhu et al. 2006). Field trapping tests have also shown that these alatae are caught in traps baited with $10 \mathrm{mg}$ of the soybean aphid pheromone blend. By comparison of total number of these alatae caught from pheromone traps and mean number of soybean aphids per plant (based on scouting 30 plants randomly in each field), the peak catch is approximately 10-14 days earlier than the highest abundance of soybean aphids in the field (Fig. 10.3). These results suggest that it may be possible to use the trap catch to establish an early warning system for monitoring soybean aphid outbreaks.

\subsection{Semiochemical-based biological control}

The use of predatory insects and parasitoids, as biological control agents to suppress population of pest species on either economically important crops or in home gardens, is well recognized by the general public and by biological control practitioners (Obrycki and Kring 1998). There have been significant successes in using coccinellids and chrysopids to suppress whitefly, aphid, mealybug, scale, and mite populations (Gerling 1990; Frazer 1988; New 1991). The use of natural enemies as biological control agents for soybean aphids has great potential to suppress soybean aphid populations (Rutledge et al. 2004). However, the biggest concern for the success of soybean aphid biocontrol is how to recruit predaceous insects into natural or damaged soybean fields and synchronize their presence with the targeted aphid pest, thereby increasing their predatory efficacy. Several 

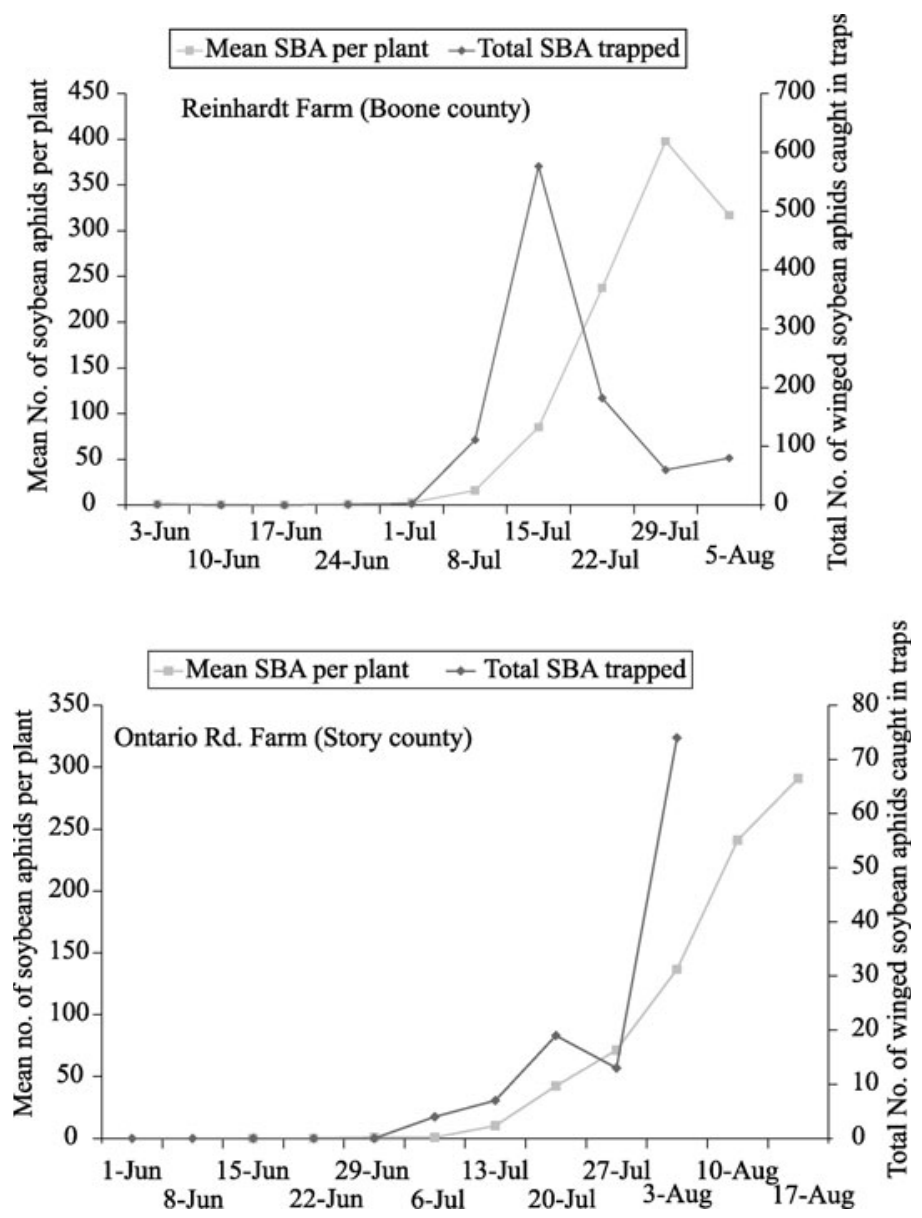

Fig. 10.3 Comparisons of total number of alatae soybean aphids caught in pheromone traps and mean number of soybean aphids per plant in two soybean fields (Iowa, USA, 2005).

predatory insects and parasitoids have been demonstrated to use semiochemicals associated with host or the host plant habitat to locate their prey (Barbosa and LeTourneau 1988; Turling et al. 2002; Vet and Dicke 1992). Zhu and Park (2005) studied the soybean plant response to aphid infestation, and showed that the plant induced defensive compound, methyl salicylate, and 2-phenylethanol (also associated with soybean plant) are attractive to several beneficial insects of soybean aphids (Fig. 10.4).

Van der Werf et al. (2000) and James (2003) have reported on the use of artificial lures to attract and retain predators in alfalfa fields and hop yards. Field trials to determine the impact of predators on soybean aphid dynamics have 


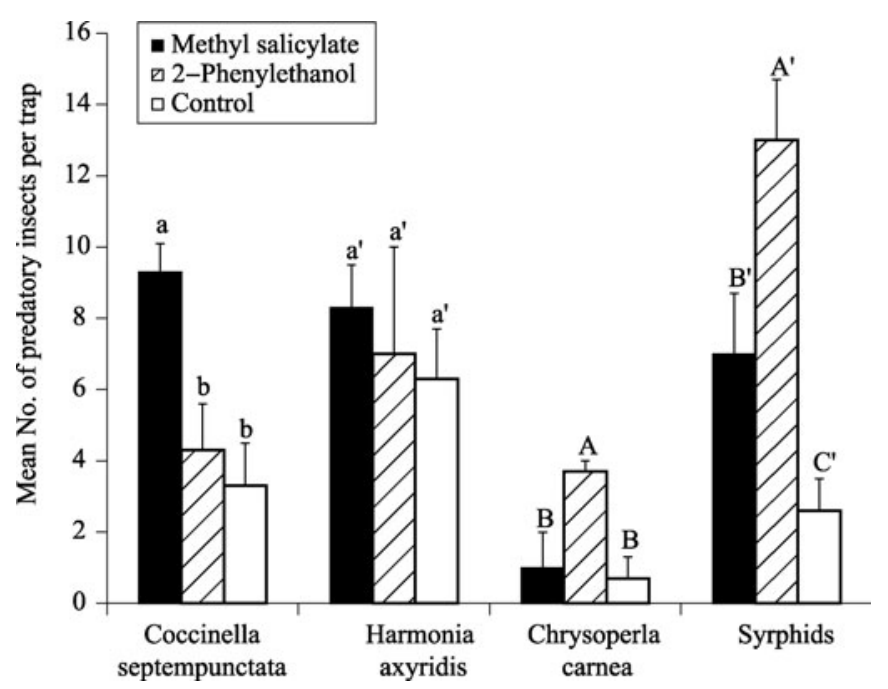

Fig. 10.4 Mean number of predatory insects (both sexes) caught in traps baited with $100 \mathrm{mg}$ of methyl salicylate and 2-phenylethanol, and the control from an Iowa soybean field in 2003. Columns with no letters in common in four different categories are significantly different ( $n=10$, ANOVA followed by FPLSD test, $P<0.05)$.

revealed that early season predation on soybean aphids can cause significant reductions of their later immigration to soybeans (Rutledge et al. 2004; Fox et al. 2004). The manipulation of these predatory insects to be synchronized with the soybean aphid appearance can be achieved by applying beneficial insect attractant lures during the earlier season in aphid-infested soybean field. Field applications using controlled release packets (developed by MSTRS Technologies, Inc.) ${ }^{1)}$ containing these two attractant compounds (Predalure with 2phenylethanol and Me-SA lure with methyl salicylate) have shown significant increases in number of beneficial insects and the suppression of soybean aphid populations in the treated fields (Fig. 10.5). Meanwhile significant more pods are produced from soybean. Plants in plots treated with the attractant lures or combined with sugar water, compared to those from plots treated with the control, or sugar water alone (Fig. 10.6, upper). An increase of $50 \%$ on pod weight has also been shown in treated plots (Fig. 10.6, lower). A further field trial with the application of beneficial insect lures in aphid-infested soybean fields showed that soybean yields from the treated field was $1,424 \mathrm{~kg}$ versus $1,284 \mathrm{~kg}$ from the control field (two fields at a size of $\sim 30,000 \mathrm{~m}^{2}$, each, and the treated field was deployed with 30 lures of each, and the lures were replaced monthly during the 5month experimental period).

1) This article reports the results of research only. Mention of a proprietary product does not constitute an endorsement or a recommendation for its use by USDA 

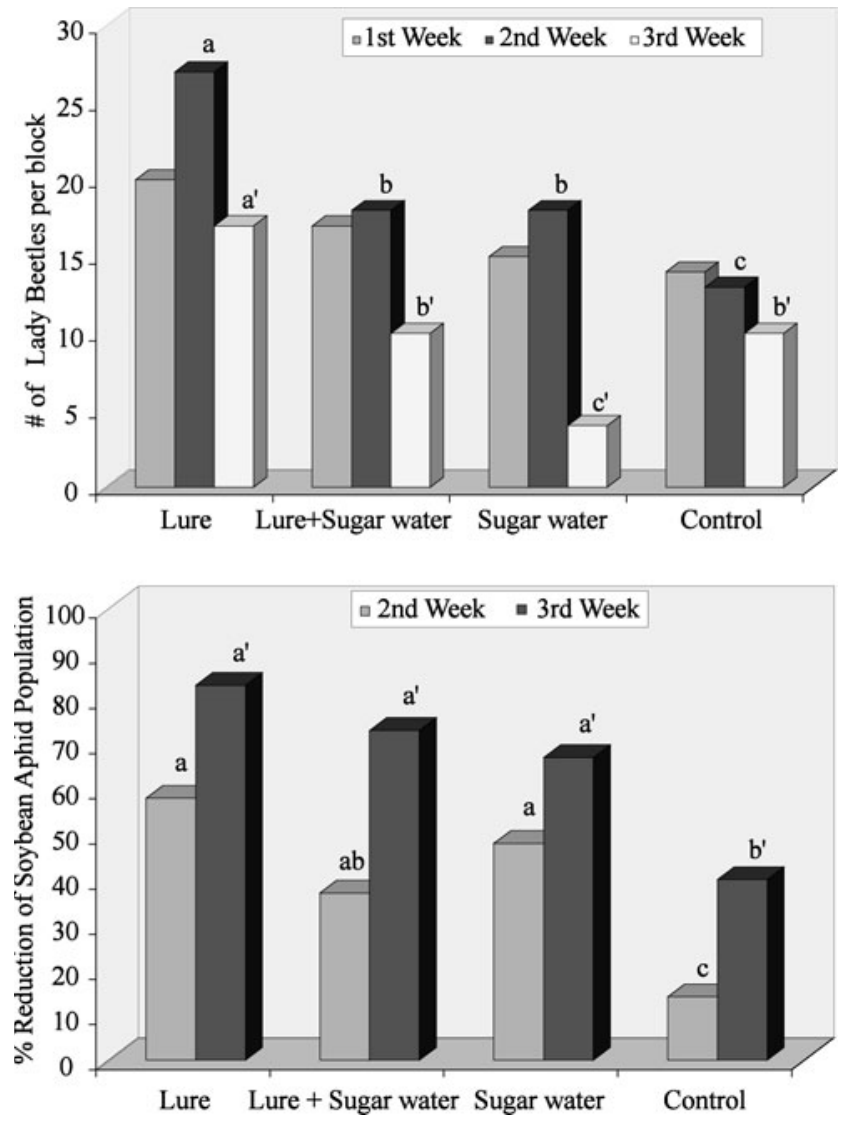

Fig. 10.5 Effects of applications of beneficial insect attractants on soybean aphid and their beneficial insect populations in the soybean field. Lure: Predalure and Me-SA lure; Lure + Sugar water: lures with the spray of sucrose application (250 grams of sucrose in one liter of water); Sugar water: sucrose application only; Control: blank. (ANOVA followed by a type III test, $F=23.3$; df $=3,184 ; P<0.01$, SAS Institute 1999).

\subsection{Summary}

In summary, the present chapter presents a unique case of exploring novel integrated aphid management strategies using infochemical tritrophic interactions among the aphid, host plants, and natural enemies. Such practices can also benefit other agricultural pest management, particularly for organic crop growers where application of chemical pesticides is not an option. However, some of these practices may be laborious and costly than the traditional approach, and need additional developments to reduce costs before the fully deployment of this new strategy. 

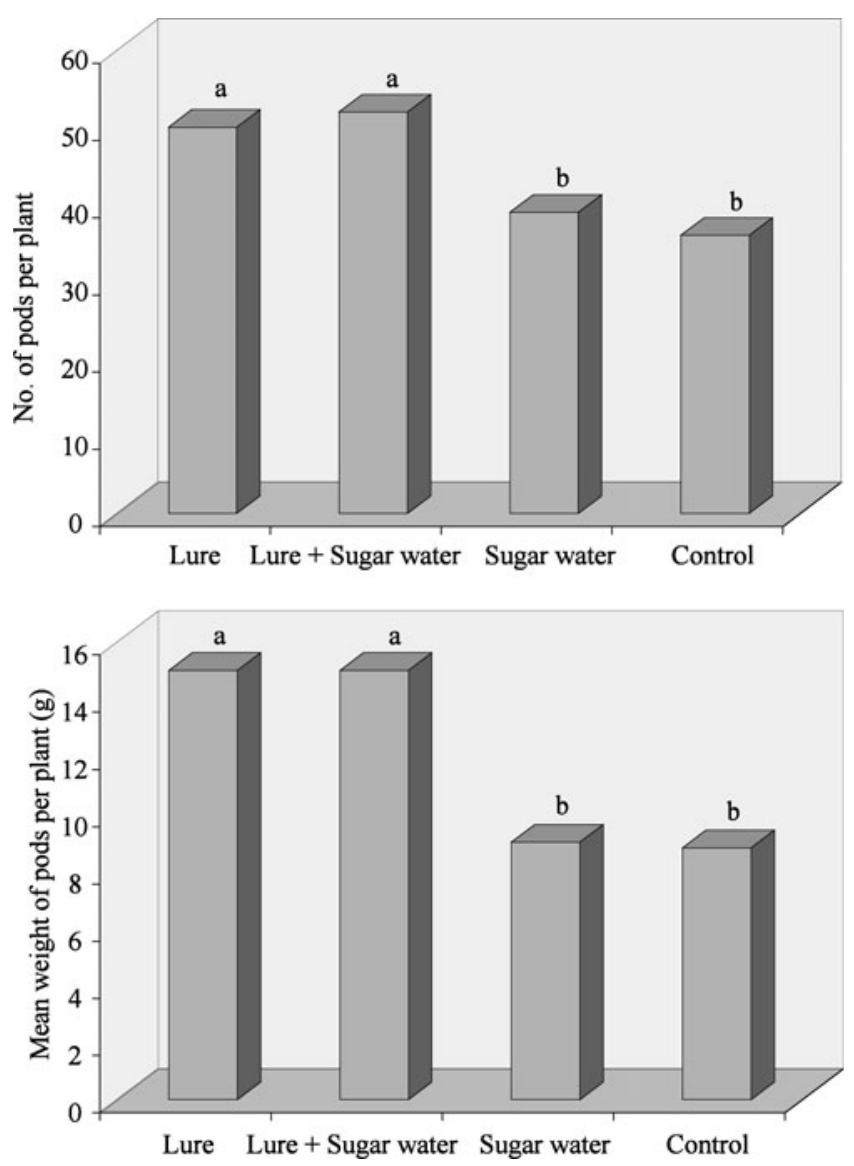

Fig. 10.6 Comparisons of number of pods and pod weights from soybean plants collected from the treated fields and control fields (ANOVA followed by a type III test, $F>4.3 ; \mathrm{df}=3,16 ; P<0.05$, SAS Institute 1999).

Acknowledgements This project was funded by National Science Foundation-SBIR program, Iowa Department of Natural Resources and The Leopold Center for Sustainable Agricultures to J. Zhu. I will also thank J. Jones, J. Heath, T. Liu and B. Ellingson for their technical supports during the course of research. Suggestions and comments from Drs. J. Obrycki and B. Wienhold on an earlier version of the manuscript are especially appreciated.

\section{References}

Baker T C, Mafra-Neto A, Dittl T, Rice M E. A novel controlled-release device for disrupting sex pheromone communication in moths, // P. Witzgall and H. Arn. Technology transfer in mating disruption. Montpellier: IOBC wprs Bulletin, 1997, 20: 141-149.

Barbosa P, LeTourneau D K. Novel Aspects of Insect-Plant Interactions. Wiley, New York, 1999. 
Boo K S, Choi M Y, Chung I B, et al. Sex pheromone of the peach aphid, Tuberocephalus momonis, and optimal blends for trapping males and females in the field. J. Chem. Ecol., 2000, 26: 601609.

Campbell C A M, Dawson G W, Griffiths D C, et al. Sex attractant pheromone of damson-hop aphid Phorodon humuli (Homoptera, aphididae). J. Chem.Ecol., 1990, 16: 3455-3465.

Chicago Tribune - Knight Ridder/Tribune Business News. 2003. Soybean aphids drain production of Midwestern cash crops. Oct. 11.

CNN News (Associated Press). 2003. Aphids whittling soybean farmers' profits. Nov. 25.

Dawson G W, Griffiths D C, Merritt L A, et al. Aphid semiochemicals-a review, and recent advances on the sex pheromone. J. Chem. Ecol., 1990, 16: 3019-30.

Du Y J, Yan F S, Han X L, Zhang G X. Olfaction in host selection of the soybean aphid Aphis Glycine. Acata. Entomol. Sinica., 1995, 37: 385-391.

Fox T B, Landis D A, Cardoso F F, Difonzo C D. Predators suppress Aphis glycines Matsumura population growth in soybean. Biol. Control, 2004, 33: 608-618.

Frazer B D. Coccinellidae. // AK Minks, P Harrewijn. Aphids-Their Biology, Natural Enemies and Control, Vol. B, New York, Amsterdam: Elsevier, 1988: 231-247.

Gerling D. Natural enemies of whiteflies: predators and parasitoids. // D. Gerling. Whiteflies: Their Bionomics, Pest Status and Management. Andover: Intercept Ltd., 1990: 147-85.

Goldansaz S H, Dewhirst S, Birkett M A, et al. Identification of two sex pheromone components of the potato aphid, Macrosiphum euphorbiae (Thomas). J. Chem. Ecol., 2004, 30: 819-834.

Hardie J, Nottingham S F, Dawson G W, et al. Attraction of field-flying aphid males to synthetic sex pheromone. Chemoecology, 1992, 3: 113-117.

Hardie J, Storer R J, Cook F J, et al. Sex pheromone and visual trap interactions in mate location strategies and aggregation by host-alternating aphids in the field. Physiol. Entomol., 1996, 21 : 97-106.

James D G. Synthetic herbivore-induced plant volatiles as field attractants for beneficial insects. Environ. Entomol., 2003, 32: 977-982.

Kobayashi M, Wada T, Inoue H. A comparison of communication disruption technique and masstrapping technique for controlling moths using sex pheromone of Spodoptera litura (F.) (Lepidoptera: Noctuidae). Proc. Japan/USA Symp. On IPM., 1981, p32-40.

Lösel P M, Lindemann M, Scherkenbeck J, et al. The potential of semiochemicals for control of Phorodon humuli (Homoptera: Aphididae). Pestic. Sci., 1996a, 48: 293-303.

Lösel P M, Lindemann M, Scherkenbeck J B, et al. Effect of primary-host kairomones on the attractiveness of the hop-aphid sex pheromone to Phorodon humuli. Entomol. Exp. Applic., 1996b, 80: 79-82.

Midwest States Soybean Aphid Management Workshop, Feb. 5, 2004. http://www.ipm.uiuc.edu/ fieldcrops /insects/soybean_aphids/Workshop/ index.html

New TR. 1991. Insects as Predators. Kensington, Aust.: NSW Univ. Press. 178 pp.

Obrycki J J, Kring T J. Predaceous Coccinellidae in biological control. Annu. Rev. Entomol., 1998, 43: 295-321.

Pickett J A, Wadhams L J, Woodcock C M. The chemical ecology of aphids. Annu. Rev. Entomol., 1992, 37: 67-90.

Ragsdale D W, Voegtlin D J, O'Neil R J. Soybean aphid biology in North America. Ann. Entomol. Soc. Am., 2004, 97: 204-208. 
Rutledge C E, O’Neil R J, Fox T B, Landis D A. Soybean aphid predators and their use in IPM. Ann. Entomol. Soc. Am., 2004, 97: 240-248.

Turlings T C J, Gouinguené S, Degen T, et al. The chemical ecology of plant-caterpillar-parasitoid interactions. // Tscharntke and Hawkins. Multitrophic Level Interactions. Cambridge: Cambridge Univ. Press, 2002: 148-173.

SAS Institute Inc., SAS OnlineDoc ${ }^{\circledR}$, Version 8, Cary, NC: SAS Institute Inc., 1999.

Smit N E J M, Downham M C A, Laboke P O, et al. Mass-trapping male Cylas spp. With sex pheromones: a potential IPM component in sweet potato production in Uganda. Croprot., 2001, 20: 643-651.

Snaders C J. Mechanisms of mating disruption in moths. // Cardé R T, Minks A K. Insect Pheromone Research New Direction. New York: Chapman \& Hall, 1997: 333-346.

Soybean Aphid Watch 2003. http://www.ipmcenters.org/northcentral/ saphid/

Van der Werf W, Evans E W, Powell J. Measuring and modeling the dispersal of Coccinella septempunctata (Coleoptera: Coccinellidae) in alfalfa fields. Eur. J. Entomol., 2000, 97: 487493.

Vet L E M, Dicke M. Ecology of infochemical use by natural enemies in tritrophic context. Annu. Rev. Entomol., 1992, 37: 141-172.

Voegtlin D J, O’Neil R J, Graves W R. Test of suitability of overwintering host of Aphis glycines: Identification of a new host association with Rhamnus alnifolia. Ann. Entomol. Soc. Am., 2004, 97: 233-234.

Zhu J, Park K C. Methyl salicylate, a soybean aphid-induced plant volatile attractive to the predator Coccinella septempunctata. J. Chem Ecol., 2005, 31: 1733-1746.

Zhu J, Zhang A, Park K C, et al. Sex pheromone of the soybean aphid, Aphis glycines Matsumura, and its potential use in semiochemical-based control. Environ. Entomol., 2006, 35: 249-257. 